\title{
Risk Classification in Natural Catastrophe Insurance: The Case of Italy
}

\author{
Donatella Porrini ${ }^{1}$ \\ ${ }^{1}$ Università del Salento - Ecotekne, Via per Monteroni, Lecce, Italy \\ Correspondence: Donatella Porrini, Università del Salento - Dipartimento di Scienze dell'Economia, Via per \\ Monteroni - 73100 Lecce (LE), Italy.
}

Received: October 27, 2015

Accepted: November 23, $2015 \quad$ Online Published: December 4, 2015

doi:10.5430/ijfr.v7n1p39

URL: http://dx.doi.org/10.5430/ijfr.v7n1p39

\begin{abstract}
The role of risk classification as a remedy for asymmetric information market failure is widely recognized and adverse selection is commonly expected to cause market failure also in natural disaster insurance market. Actually, natural catastrophe insurance is a hot topic for the fact that national governments need to build a system to face the high cost of disaster assistance and damage compensation. But an efficient natural disaster insurance is based also on a coherent risk classification and this is the key point of the paper. We argue that issues of risk classification should be a major concern in the design of natural disaster insurance, especially in countries, such as Italy, with a so low penetration of this kind of insurance. The paper is structured as follows. Section 2 provides information on the Italian NatCat insurance. Section 3 describes risk classification looking at the demand side of the market. Section 4 analyses adverse selection in NatCat insurance market and the role of risk classification. Section 5 concludes.
\end{abstract}

Keywords: insurance market, asymmetric information, risk classification

\section{Introduction}

Actually, natural catastrophe (NatCat) insurance is a hot topic for the fact that national governments need to build a system to face the high cost of disaster assistance and damage compensation (Porrini, Schwarze, 2014).

Insurance could play an important role in managing natural hazard risks and promoting recovery from disasters, but insurance coverage may result in moral hazard if insured individuals take fewer measures to limit risk if they expect that insurers will compensate their damage irrespective of their mitigation. Moreover, adverse selection may obstruct the adequate functioning of natural disaster insurance markets if mainly individuals who face a high risk demand insurance, and insurers do not adequately factor such risks into higher prices because of information asymmetries between the insurer and the insured.

Risk classification can play a role as a remedy for adverse selection and moral hazard, as it is widely recognized (Hoy, 1982; Abraham, 1985). But this is not the only role in the case of building an efficient natural disaster insurance national system.

The objective of the paper is to demonstrate that risk classification should be a major concern in the design of natural disaster insurance, especially in countries, such as Italy, with a so low penetration of this kind of insurance.

The paper is structured as follows. Section 2 provides information on the Italian NatCat insurance. Section 3 describes risk classification looking at the demand side of the market. Section 4 analyses adverse selection in NatCat insurance market and the role of risk classification. Section 5 concludes.

\section{Natural Catastrophe Issue and Insurance Role}

Natural catastrophes (NatCat from now on) (Note 1) not only cause human losses but also huge damages, having potentially effects that can threaten entire areas in a country or across the countries. Governments may carry large fiscal burdens, which could cause internal and external imbalances affecting economic stability and growth.

Over the last decades economic damages from NatCat have been increasing and this trend is likely to continue. 


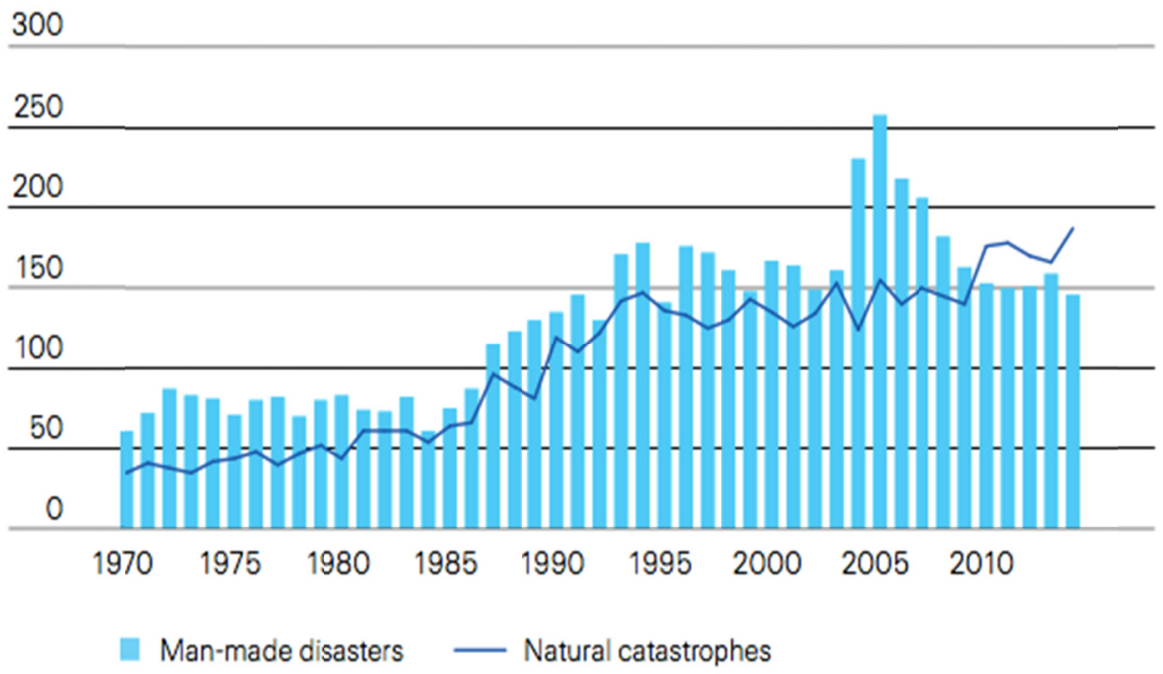

Figure 1. Number of catastrophic events in the world

Source: Swiss Re (2015)

Economic development, population growth, a higher concentration of assets in exposed areas and a changing climate are going to increase the economic cost of NatCat.

Insurance could play an important role in managing this kind of risks and promoting recovery from disasters, because insurance reduces financial risks for households by spreading risks over many policyholders, and helps economically people after a disaster occurs. Insurance can also provide incentives for risk reduction by charging premiums that act as a price signal of risk, or by providing premium discounts to policyholders who protect their property against disaster consequences (Kunreuther, 1996).

The increasing trend in catastrophic events, shown in Figure 1, should be accompanied by a commensurate insurance penetration. But this is not the case, as we can see in Figure 2 through the relation between insured and uninsured losses.

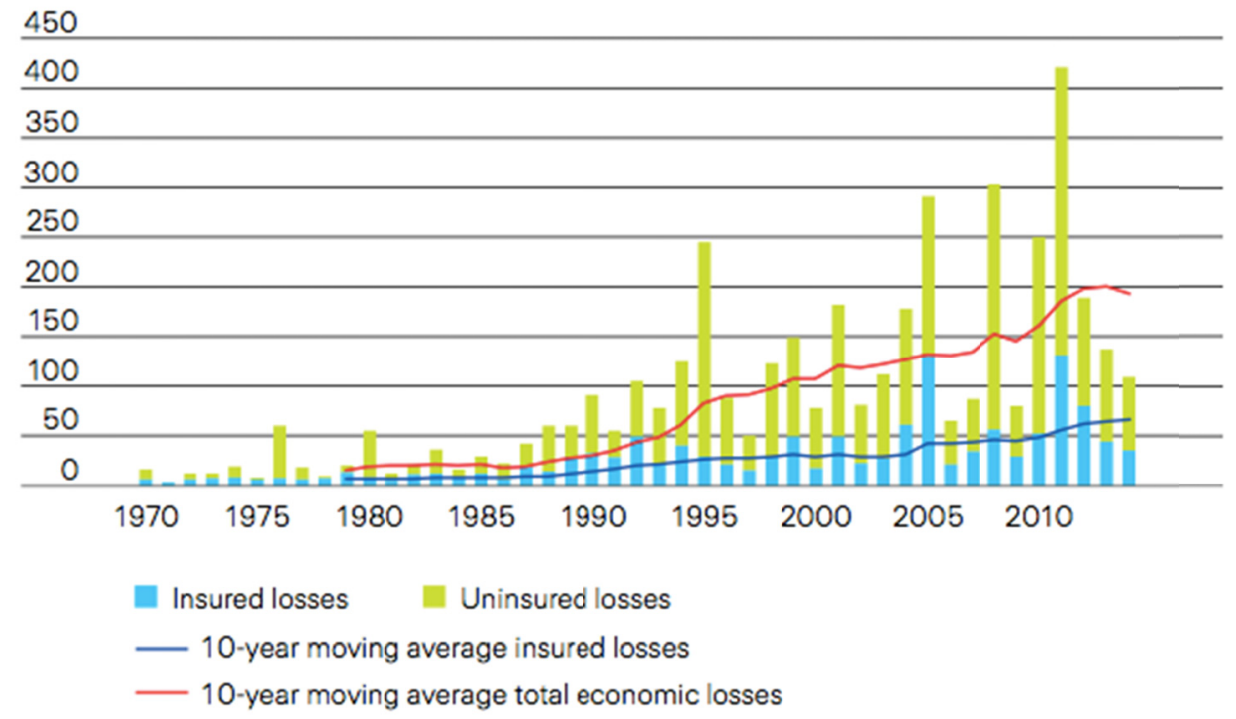

Figure 2. Insured vs uninsured losses (USD billion in 2014 prices)

Source: Swiss Re (2015) 
Currently, existing natural disaster insurance schemes are under financial distress in a number of countries. Furthermore, many countries, such as Italy, do not have an adequate system of protection against the financial and economic consequences of natural disasters. The call for reforms of existing, or implementation of new, institutional frameworks for natural disaster insurance is evident.

Extensive work on NatCat risks has been undertaken and/or initiated in the EC in recent years, partly in response to evidence that the probability and impact of NatCat will be negatively affected by climate change.

A quick reference to NatCat insurance was made in the EC Communication (2009): "Between 1990 and 2007 the European Union witnessed a marked increase in the number and severity of both natural and man-made disasters, with a particularly significant increase in the former. The loss of human life, the destruction of economic and social infrastructure and the degradation of already fragile ecosystems is expected to worsen as climate change increases the frequency and magnitude of extreme meteorological events, such as heat waves, storms and heavy rains".

A further reference may be found in the White Paper on Climate Change (2009): "Optimising the use of insurance and other financial services products could also be explored. It should be evaluated whether certain private actors/sectors (such as those providing public services, critical infrastructure) need to be covered by compulsory standard weather-related insurance.

In cases where insurance is not available, for example for buildings located in flood plains, publicly supported insurance schemes may be required. Due to the cross-border effects of natural disasters, there may be benefits in promoting EU-wide insurance as opposed to national or regional schemes".

On 9 March 2010, Commissioner Michel Barnier announced that the European Commission would carry out an in-depth examination of insurance schemes covering national catastrophes, in particular flooding. Moreover this initiative would involve a dialogue with Member States and insurance experts on examples of best practice.

In 2012, a specific Report of the Joint Research Centre (JRC) has been issued with the aim "to assemble information on Natural Catastrophes across European Member States and on the insurance practices in place".

This is the first time for the EU to directly focus on the role of insurance in relation to NatCat risks. The focus of the JRC Report is on flood, storm, earthquake, and drought. For each of these catastrophe types, the JRC has collected both qualitative and quantitative information from a number of different sources. For every member State the JRC has processed available information in order to describe the size of NatCat and detail existing practices of insurance systems, focusing in particular on: detecting which NatCat can be considered as relevant in any given member State; for relevant risks, investigating if there exists a market of dedicated insurance products; identifying the main issues and open problems.

The collected information has the purpose to create clusters of States facing similar problems and to identify open issues concerning insurance systems in place. For the first goal quantitative information on the size of economic losses related to each NatCat is analyzed. For the second goal these data are combined with other available information on bundling practices, pricing approaches and role of Government in the various countries.

Finally in 2013, the prospect of growing impacts from NatCat due to climate change and socio-economic growth and the relevant role of insurance have launched the Green Paper on the insurance of natural and man-made disasters, which reflects on the concerns about rising risk levels and how this can be accommodated through new and existing insurance schemes. The consultation document frames insurance in two ways: the question of availability and affordability, and the potential to use insurance as a lever for prevention and disaster damage mitigation. "Private insurance can address a number of related policy concerns and can contribute to sustainable public finances. Insurance is one of the tools for disaster risk management, together with risk prevention, preparedness and response measures: a functioning disaster risk insurance system, beyond risk sharing, can be operational at all levels of the risk management cycle, from risk identification and risk modelling to risk transfer and recovery. Insurance has a specific role: it does not prevent the loss of lives or assets but helps to reduce the economic impact and facilitates recovery after disasters. Well-designed insurance policies can also work as a market based instrument to discourage risky behaviour and promote risk awareness and mainstream disaster proofing in economic and financial decisions".

\section{Natural Catastrophe Exposure and Insurance in Italy}

Italy is exposed to a high level of natural catastrophe risks, due to its natural characteristics and anthropological factors. Since 1900, earthquakes have caused around 160,000 deaths in Italy, while since the Second World War alone, there have been 1,061 lethal landslides, and at least 672 fatal floods. Hydrogeological events have claimed over 9,000 lives, with over 700,000 people left displaced and homeless. 

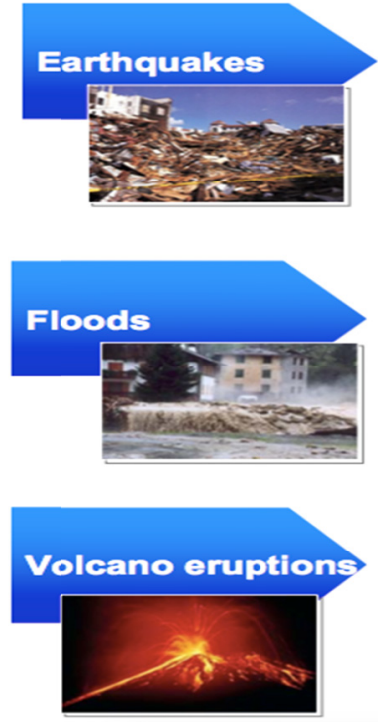

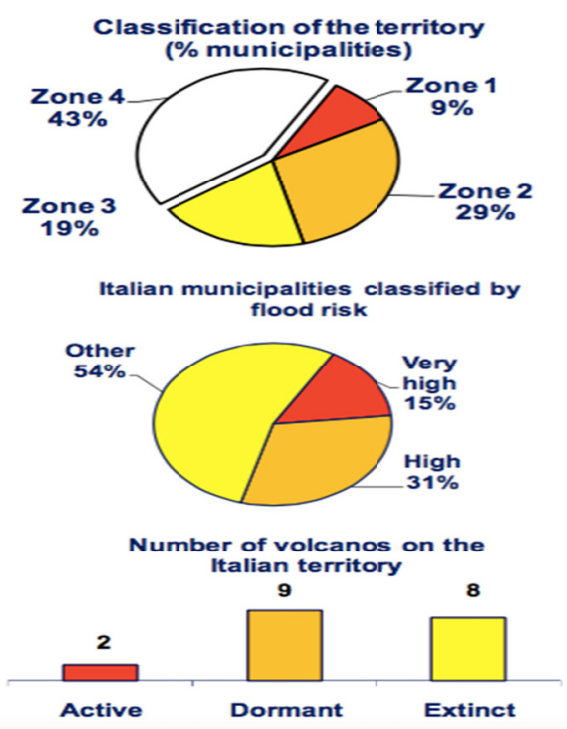

Figure 3. Exposure to NatCat risks in Italy - 2010

Source: ANIA (2011)

As we can see in Figure 3, a relevant part of Italian municipalities is in seismic risky areas. This is also due to Italian geographic positions. Around 3,671 municipalities, that is $45.3 \%$, are classified as having a "high" or "very high" flood risk. For what concerns volcano eruptions, Etna coastline, the Stromboli and Neapolitan areas, represent the areas with a higher risk.

In Italy, despite the high exposure, NatCat insurance market has not developed in the years. Recently it has been estimated that, given the percentage of $44 \%$ of private buildings that have a fire insurance policy, less than $0.5 \%$ of such policies have additional natural catastrophes cover.

Table 1. Penetration rates in European countries - 2011

\begin{tabular}{|c|c|c|c|c|}
\hline & Flood & Storm & Earthquake & Drought \\
\hline BE & $>75 \%$ & $>75 \%$ & $>75 \%$ & \\
\hline BG & $<10 \%$ & $<10 \%$ & $<10 \%$ & \\
\hline CZ & $25-75 \%$ & $25-75 \%$ & $25-75 \%$ & $<10 \%$ \\
\hline DK & & $>75 \%$ & & \\
\hline DE & $25-75 \%$ & $>75 \%$ & $25-75 \%$ & \\
\hline \multicolumn{5}{|l|}{ EE } \\
\hline IE & $>75 \%$ & $>75 \%$ & $>75 \%$ & \\
\hline GR & $<10 \%$ & $<10 \%$ & $<10 \%$ & \\
\hline ES & $25-75 \%$ & $25-75 \%$ & $>75 \%$ & $<10 \%$ \\
\hline FR & $>75 \%$ & $>75 \%$ & $>75 \%$ & $>75 \%$ \\
\hline IT & $<10 \%$ & $<10 \%$ & $<10 \%$ & \\
\hline \multicolumn{5}{|l|}{ CY } \\
\hline \multicolumn{5}{|l|}{ LV } \\
\hline \multicolumn{5}{|l|}{ LT } \\
\hline LU & $<10 \%$ & $>75 \%$ & & \\
\hline \multicolumn{5}{|l|}{ HU } \\
\hline \multicolumn{5}{|l|}{ MT } \\
\hline NL & & $>75 \%$ & & \\
\hline AT & $10-25 \%$ & $>75 \%$ & $<10 \%$ & $10-25 \%$ \\
\hline PL & $25-75 \%$ & $>75 \%$ & & \\
\hline PT & $25-75 \%$ & $25-75 \%$ & $<10 \%$ & \\
\hline RO & & $<10 \%$ & $<10 \%$ & \\
\hline SI & $25-75 \%$ & $>75 \%$ & $25-75 \%$ & \\
\hline \multicolumn{5}{|l|}{ SK } \\
\hline FI & $10-25 \%$ & $>75 \%$ & & \\
\hline SE & $>75 \%$ & $>75 \%$ & $>75 \%$ & $>75 \%$ \\
\hline UK & $>75 \%$ & $>75 \%$ & $>75 \%$ & \\
\hline
\end{tabular}

Source: ECJRC (2012) 
As we can see in Table 1, Italy is one of the European countries with the lowest penetration of NatCat insurance, considering that penetration rates vary very much in the EU Member States.

The reasons for these differences are identified by the literature in the followings: the legislative provisions, the State participation in insurance system, the nature of the disaster risks to be insured, the insurance culture, and others.

The European Parliament (2013) outlined that "the situation in the EU insurance market is heterogeneous because Member States are exposed to different risks and natural catastrophes and the predictability of a natural catastrophe depends on different factors (meteorological, hydrological, geophysical, etc.)".

In general, the penetration rate for more frequent events (e.g. storms and hail) is higher than for less frequent disasters (e.g. earthquakes and flooding), and the distribution is concentrated in those areas where the risk is actually perceived. It should be noted, furthermore, that cover for earthquakes and flooding requires large reserves of capital, not always easily available to operators.

Given a potential high exposure of a country but also low insurance penetration, such as in Italy, in general terms, public interventions can be or ex-ante or ex-post: it can be on the prevention side with the objective to reduce the probability and impact of NatCat (e.g. via flood barriers, regulation of building on flood plains, etc.), or it can be an ex-post Government response, including aid for victims and restoration of public services. But at the same time also the market of NatCat insurance is clearly affected by the size of preventive measures as well as by ex-post Government interventions (Note 2).

Furthermore, Italian government needs to reduce the high tax pressure on citizens and in this perspective the public sector cannot rely on public finance to bear the cost of rebuilding areas damaged by natural disasters, for example through the taxes increase or the ex-post introduction of new ad hoc taxes.

In the past, public disaster relief was often followed by new tax burdens (additional income tax or VAT tax) or parafiscal taxes (increase in the excise tax on petrol) that applied to all citizens. In addition, these taxes were not eliminated once the repair or reconstruction work was completed (Note 3).

So Italy is characterised by a public dependency on government support in the wake of disastrous events but such a kind of system can no longer be afforded to cover all financial losses.

Since 90ies, many proposals for various draft laws tried to discipline and fix the principles to build an efficient insurance market for NatCat coverage. Budget Law in 2005 introduced a voluntary insurance regime to cover risks deriving from natural catastrophes on buildings, no matter what their use is, sets up a Guarantee Fund managed by Consap SpA and provided for a public expenses of 50 millions Euros.

After the tragedy which struck L'Aquila (6 April 2009), the issue of introducing an insurance scheme against natural catastrophes has come back in public debates and in the political agenda. Some crucial points in the proposal come from the insurance sector, also in the wake of the proposal made by Minister Renato Brunetta (inspired to the US's National Flood Insurance Program), such as: a compulsory system covering private dwellings; the State as last resort reinsurer upon payment of a premium; local bodies collaboration in planning prevention measures and in mapping risks; a market regime with differentiated prices also on the base on construction methods (which encourages good building practices); the setting-up of consortia or smoothing funds.

The crucial point in Italy, from a market perspective, is the establishment of adequate operational mechanisms for which the insurance sector would be financially capable of bearing the cost of insuring all of Italy's residential properties. On a demand point of view, it is necessary to have a sufficient penetration of this kind of insurance; on a supply side point of view, the premium rate must be applied to insured properties in order for the company to sustain the cost of the damages resulting from this kind of events.

To develop a system based on the diffusion of NatCat insurance, tax incentives may be necessary to benefit those who choose to purchase disaster insurance. Currently, premiums for insurance coverage of this type are taxed at a rate of $22.25 \%$, the highest rate provided by Italian law and the highest in Europe (Figure 4). 


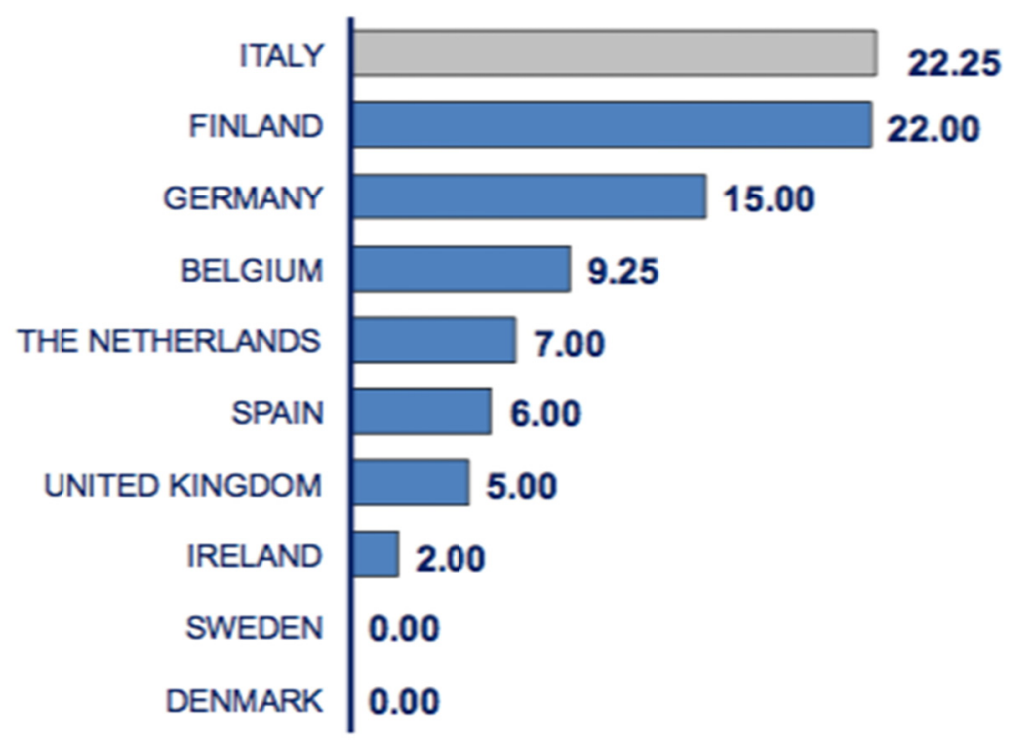

Figure 4. Tax rate (\%) on fire premiums in some European countries -2010

Source: ANIA (2011)

As it is in the public interest the penetration of Nat Cat policies to be more widespread, this rate could be significantly reduced. For example, the rate could be decreased to the same rate used for auto insurance, which is fixed at $12.5 \%$, given that legislators have deemed certain types of coverage to be worthy of protection, providing an even lower tax rate.

Another fiscal intervention could be to make premiums tax deductable from personal income tax (IRPEF): the premium could be deducted from taxable income, thereby reducing the gross tax, or a percentage of the premium (for example, in the "ordinary" measure $19 \%$ of the amount paid) could be deducted directly from the income tax due. The first case (deduction from taxable income) would be more favourable for policy holders with higher incomes, while the second case (deduction of a percentage of the premium from the income tax due) would be more beneficial for policy holders with lower incomes. An alternative would be to offer policy holders a tax credit to lessen the financial burden.

Given the opportunity to fiscally support the diffusion of NatCat insurance, another very relevant point is the development of an efficient risk classification system and this would positively affects both the demand and the supply side of the market, as we will see in the next paragraphs.

\section{The Effects of Risk Classification on the Demand Side}

The variety of natural catastrophe insurance purchased in Member States also reflects the diversity in the public's perception of the actual risks presented by possible catastrophes. This can be a consequence of the underestimation of the insurance needed due to a lack of information about the risk and/or a lack of awareness of the magnitude of the risk.

The lack of effective information, especially when it concerns probabilistic information regarding catastrophes, causes people having difficulties judging risk assessments in terms of relative frequency (Slovic, Monahan and MacGregor 2000).

Generally, on the demand point of view, individuals used to show difficulties in assessing low-probability/high-impact risks with which they have few experiences such as natural disasters. This may translate into poor decision making with respect to natural disaster insurance purchase. This is generally called the "it will not happen to me" attitude and have relevant implication in the insurance purchasing decision (Note 4).

A key element to improve the risk perception is "risk communication": an effective risk communication informs people at risk about the key determinants of their "vulnerability". 
So it is important to focus on developing a comprehensive risk management system, including risk zoning, hazard mapping, and building codes. And in this sense, a relevant role is played by the dissemination of a risk classification system that can be easily interpreted and integrated into the decision-making process to purchase an insurance policy.

Some European countries have adopted a system that makes the insurance purchase obligatory or semi-obligatory by increasing as much as possible the number of people with coverage. In the case of obligatory insurance, disaster insurance is required for all property owners, while in the case of semi-obligatory insurance, for example in France, it is required only for those property owners who purchase fire insurance.

This is another way to create a larger risk pool, to make disaster insurance more affordable and to facilitate outreach to customers, bundling NatCat insurance with fire policies. In many countries bundling already takes place (e.g. Germany. Austria, UK, France, Spain and Switzerland). But the use of this kind of insurance may be limited by the nature of the catastrophe and the characteristics of the country: if one peril clearly prevails bundling of perils does make less sense than for countries with equally important perils.

Another aspect of risk classification is in determining the premium to be charged for insurance coverage. In fact the insurance companies utilise risk classification systems in an attempt to assure that individuals are grouped in such a way that those with a similar possibility of loss are charged the same rate. Applying risk classification, the insurer aggregates uncorrelated, that is independent, risks and segregate these risks into separate risk pools (Note 5).

By the use of risk classification, NatCat insurance can be priced on a risk-based mechanism that may provide signals to individuals regarding the hazards they face, thus encouraging the adoption of measures that may lie within their capacity to address and promoting risk management.

As the European Parliament (2013) noted "Recalling that natural catastrophes affect both private households and business activities, Parliament encouraged insurance companies to take risk-based pricing as a central approach to disaster insurance. It invited Member States to propose incentives to encourage citizens to protect themselves and insure their property against damage, and incentives responding to insurance needs in terms of environmental liability, e.g. for enterprises in mining or in the gas, chemical or nuclear sectors".

The way NatCat coverage is priced among EU member states is very heterogeneous. Some member states adopt a risk-based pricing mechanism. For example, in Germany and UK insurance companies utilize risk zoning systems to assess the premiums for flood and storm. Other countries adopt flat pricing, invoking the principle of solidarity. Flat rates also have different features: they can be a fixed percentage of the insured capital (e.g. Spain), a percentage of the premium paid for a base contract to which the NatCat insurance is bundled (e.g. France), or they can be in the form of a fixed charge included in the fire insurance (e.g. Denmark).

Also making insurance policies more affordable is likely to increase insurance demand, as more people may consider buying insurance at the lower rate. So, financial support from governments to subsidise the cost of premiums or lower the level of risk by establishing prevention measures can have a positive effect on insurance penetration.

Many effects of risk classification are on the supply side and this issue will be addressed in the next paragraph.

\section{The Effects of Risk Classification on the Supply Side}

On the supply side, risk classification is the basic device for reducing the problems connected with asymmetric information, and particularly adverse selection.

In fact, adverse selection, as the tendency of persons with relatively greater exposure to risk to seek insurance protection, can be efficiently controlled if the insurance company is successful in collecting into a risk pool individuals with a narrow range of exposure to risk for the insurance to remain financially attractive to each member of the pool. Otherwise, if the disparity between the premium and the risks added by low-risk members becomes too substantial, low risk members may drop out of the pool.

Specifically, adverse selection may obstruct the adequate functioning of NatCat insurance markets if mainly individuals who face a high risk demand insurance, and insurers do not adequately factor such risks into higher prices because of information asymmetries between the insurance company and the insured.

Insurers employ a variety of methods to narrow risk pools and distinguishing in these various ways among insureds increases the availability of insurance because it makes market insurance more attractive to relatively low-risk individuals. This fact is attributable to the insurance industry practice of placing policyholders into groups who supposedly have a similar probability of loss: individuals within each group are then charged a similar premium. 
Generally, by identifying independent risks and aggregating them into a risk pool, the insurer increases predictive accuracy by exploiting the law of large numbers. So in the case of NatCat, it is particularly important for insurers to have geographically diversified risk portfolios in this case, as natural catastrophes strike large areas at once and lead to simultaneous losses.

The distinctions utilised in the risk classification system are clearly supported by statistical data showing differences in probability of the different groups. So, in the reality, large differences in premiums paid by individuals for identical coverage are based on discriminatory classifications but classification systems is based on different variables (Porrini 2012, 2015).

In determining whether a risk classification is efficient, we can consider some variable characteristics, such as homogeneity, separation, reliability, causality, social acceptability, and incentive value. Homogeneity means that since all members of a class pay the same rates, their risk of loss should be as close as possible. The separation measures the extent to which the classes' mean expected losses should be sufficiently different in loss expectation to warrant their identification as separate class. Reliability measures whether practical and easily observable differences are used to classify insured and so measures the accuracy of classifications. Causality measures whether class distinctions are based on characteristics causally related to loss. Social acceptability measures the extend to which a variable is consistent with public policy. Incentive value means that a fair class system should classify the characteristics within the insured's control in order to provide the incentive to adopt low risk characteristics.

Risk diversification, however, is costly, first of all for the transaction costs involved in the classification procedure and part of the costs may reasonably be passed on customers via higher premiums. So, on one side, provided the greater the risk that must be diversified, the more costly the classification becomes; on the other side, the higher is the average risk within a risk pool, the higher will be the cost of the insurance of such risks, thus the higher the premiums that members of the pool have to pay.

Definition of risk pools is, therefore, essential to the insurance function. Accurate risk-pooling, in fact, basically aims at reducing average risk faced by the insurer through reducing the range of risk within the pool. Both aggregation and segregation of risks into narrow risk pools reduce risk variance and thus serve to reduce the costs of insurance. In addition, segregation into narrow risk pools reduces adverse selection, because it makes insurance more attractive to the low-risk members of the pool. Distinction of insureds into separate risk pools according to the specific exposure to risk allows insurers to charge premiums as close as possible to the insured's expected loss, thus attracting also the relatively low-risk customers that would otherwise drop out insurance, found to be too expensive. At the end of the day, this virtuous process is increasing the availability of insurance to the whole society.

One aspect of the matter, which call for legal intervention is the insureds' lack of incentive to disclose information necessary for the insurer to define narrow risk pools. From a comparative law perspective, one could easily notice that similar rules are characterising insurance law in the main legal systems. In Common Law, for instance, the same function is performed by the "utmost good faith" (uberrimae fidei) doctrine (Note 6). The insurer can refuse to pay an insurance claim on the grounds that the insured withheld information prior to the formation of the contract. The information must be such that it would have influenced the premium that would have been charged or the insurer's decision to accept a risk. The aim of the described system of legal rules is therefore to achieve a soft of mandatory disclosure of all information deemed material for the insurer to form a proper opinion about the risk brought by each insured.

For what concerns the Italian law, this is the basic function of the legal provisions established by articles 1892 and 1893 of the Italian civil code. The deterrence effect against non-disclosure is even stronger than in Common law, in the case of fraudulent intention: the insurer can refuse to pay the claim while keeping the premiums. When inaccurate information has been provided by the insured without fraudulent intention, Italian law disposes that the benefit paid in case of occurrence of the loss is reduced to account for the higher risk (art. 1893). A similar rule applies in case of risk worsening after the insurance contract is concluded (art. 1898). Under Italian law the insured has the duty to disclose all subsequent, material information relating to the magnitude of the risk, even after the insurance has been purchased. If such duty is not fulfilled and hidden information is not otherwise detected by the insurer, the claim the latter has to pay in case of occurrence of the loss is reduced to account for the higher risk. The insurer can even refuse to pay the claim when the information at issue, if known, would have influenced his decision to accept the risk.

The importance of this issue in NatCat can be for example helping the insurability of buildings that are not up to code or illegal. Insurability is based on the declaration of the insureds about the technical aspects whether or not the building complies with the technical regulations that were in effect when it was constructed, especially for more 
recent buildings. In contrast, illegal structures do not necessarily fail to comply with such technical regulations. However, there may be solutions in the liquidation process in the event of a claim.

Risk classification in NatCat is mainly based on statistical-actuarial techniques that use the historical observation of a large number of damage-producing events and associated costs of such events. The technical aspects of risk classification make necessary to seek out tools based on geophysical, meteorological, hydrological, climatological, and biological, as we can see in the following table.

Table 2. Natural disaster events categories of risk classification

\begin{tabular}{ccc}
\hline Categories & Data needed & Cases \\
\hline Events originating from solid earth & Geophysical & $\begin{array}{c}\text { Earthquake, Volcano, Mass } \\
\text { Movement (dry) }\end{array}$ \\
\hline $\begin{array}{c}\text { Events caused by deviations in the normal water cycle and/or } \\
\text { overflow of bodies of water caused by wind set-up }\end{array}$ & Meteorological & Hydrological \\
\hline $\begin{array}{c}\text { Events caused by macro scale processes (in the spectrum of } \\
\text { climate variability) }\end{array}$ & Climatological & $\begin{array}{c}\text { Extreme Temperature, } \\
\text { Drought, Wildfire }\end{array}$ \\
\hline $\begin{array}{c}\text { Disaster caused by the exposure of living organisms to germs } \\
\text { and toxic substances }\end{array}$ & Biological & $\begin{array}{c}\text { Epidemic, Insect Infestation, } \\
\text { Animal Stampede }\end{array}$ \\
\hline
\end{tabular}

Risk classification needs accurate empirical information, such as a geological map of the region that surveys and highlights the areas of greatest risk, as well as historical information, such as past events that have been recorded. In addition to the above data, studies are conducted on the impact of the building construction methods. All of these elements are included in the risk profile.

The difficulties of the insurance companies to construct a coherent hazard mapping because of the limited availability of public official data and maps are reported also by the European Commission (2009). "Hazard mapping aims to identify the areas prone to particular risks. It provides essential information to the public and is an important tool for planning authorities. Member States are in the process of developing a number of initiatives relating to hazard and risk mapping. The diversity of methodological approaches has reduced comparability of information and makes it difficult for information to be consolidated at the European level. As a result there is no overall picture of the risks the EU is facing. Policy makers and businesses (e.g. infrastructure developers, the insurance sector) would benefit from better comparability of hazard/risk information across the EU".

\section{Conclusive Remarks}

The relevant burden placed on the public finances to deal with NatCat cannot any long be faced by taxation policy and the establishing of special funds. Most of the EC member states, and especially Italy, are now advisable to develop an insurance system. The main advantages of such a move were examined in the paper and the positive effects of risk classification has been outlined.

Usually in the literature (Skogh, 1999), public-private partnerships, or state-owned pools should be introduced to those areas where the economic risks of the possible natural catastrophes exceed the financial capacity of the private insurance market. This could be the case where the premium necessary to build enough financial capacity to cover a risk is high, which can lead to low demand for cover and an inability to build a sufficient pool for spreading the risk. Generally, public-private partnerships can be of great value also to enlarge the pool of insureds to help build insurance availability and capacity at commercially affordable premium rates.

Moreover, the paper stressed the need for greater awareness-raising efforts aimed at fostering a firmer understanding of insurance risk. We likewise recommend that a coherent risk classification be identified which would come from a more fruitful collaboration between the public and private sectors in covering disaster risks to be integrated within a wider transnational framework.

\section{Acknowledgements}

I am grateful for the useful comments of those who participated to the 16th Joint seminar of Eale and Geneva Association, Berlin 28-29 May 2015. 


\section{References}

Abraham, K. S. (1985). Efficiency and fairness in insurance risk classification. Virginia Law Review, 71, $403-451$. http://dx.doi.org/10.2307/1072963

Ania. (2011). The Importance of Insurance for Disaster Risk Reduction Policies: Lessons from The Crisis, Paolo Garonna intervention in Event on Disaster Risk Reduction in South Eastern Europe, Roma, 8th March 2011.

Browne, M. J., \& Hoyt, R. T. (2000). The Demand for Flood Insurance: Empirical Evidence. Journal of Risk and Uncertainty, 20(3), 291-306. http://dx.doi.org/10.1023/A:1007823631497

Commission of The European Communities. (2009). White Paper Adapting to Climate Change: Towards a European framework for action, COM (2009) 147 final, Brussels, 1.4.2009.

Ec Communication From The Commission To The European Parliament, The Council, The European Economic And Social Committee And The Committee Of The Regions. (2009). A Community approach on the prevention of natural and man-made disasters, Brussels, 23.2.2009 COM(2009) 82 final.

ECJRC - European Commission, Joint Research Centre Scientific Support to Financial Analysis Unit Institute for the Protection and Security of the Citizens. (2012). Natural Catastrophes: Risk relevance and Insurance Coverage in the EU, by S. Maccaferri, F. Cariboni, F. Campolongo, Version September 2012.

EEA - European Environment Agency. (2010). Mapping the Impacts of Natural Hazards and Technological Accidents in Europe - an Overview over the Last Decade. Retrieved from http://www.eea.europa.eu/publications/mapping- the-impacts-of-natural

European Commission. (2013). Green Paper on the insurance of natural and man-made disasters, Strasbourg, 16.4.2013 COM(2013) 213 final.

European Parlament. (2013). Text adopted by Parliament, single reading, 2013/2174(INI) - 05/02/2014.

Hoy, M. (1982). Categorizing Risks in the Insurance Industry. Quarterly Journal of Economics, 97(2), $321-336$. http://dx.doi.org/10.2307/1880761

Kunreuther, H. (1996). Mitigating Disaster Losses through Insurance. Journal of Risk and Uncertainty, 12, $171-187$. http://dx.doi.org/10.1007/BF00055792

Kunreuther, H., Meyer, R., \& Michel-Kerjan, E. (2013). Overcoming Decision Biases to Reduce Losses from Natural Catastrophes. Behavioral Foundations of Policy, Princeton: Princeton University Press, pp. 398-413.

Monti, A. (2002). Buona fede e assicurazioni, Giuffrè Ed., Milano.

Porrini, D. (2012). Insurance Regulation. In Roger J. Van den Bergh and Alessio M. Pacces (Eds.), Regulation and Economics, Encyclopedia of Law and Economics ( $2^{\text {nd }}$ ed., pp. 529-557). Edward Elgar Publishing. http://dx.doi.org/10.4337/9781782540465.00022

Porrini, D., \& Schwarze, R. (2014). Insurance models and European climate change policies: an assessment. European Journal of Law and Economics, 38(1), 7-28. http://dx.doi.org/10.1007/s10657-012-9376-6

Porrini, D. (2015). Risk Classification Efficiency and the Insurance Market Regulation, Risks, 3(4), $445-454$. http://dx.doi.org/10.3390/risks3040445

Raschky, P., \& Weck-Hannemann, H. (2007). Charity hazard - real hazard to natural disaster insurance. Environmental Hazard, 7, 321-329. http://dx.doi.org/10.1016/j.envhaz.2007.09.002

Rea, S. A. (1992). Insurance Classifications and Social Welfare. In G. Dionne (Ed.), Contributions to Insurance Economics (pp. 377-396). Boston-Kluwer Academic Publishers. http://dx.doi.org/10.1007/978-94-017-1168-5_15

Skogh, G. (1999). Risk-Sharing Institutions for Unpredictable Losses. Journal of Institutional and Theoretical Economics (JITE), 155(3), 505-532

Slovic, P., Kunreuther, H., \& White, F. (2000). Decision Processes, Rationality, and Adjustment to Natural Hazards, Iin Slovic, P. (Ed.), The Perception of Risk (pp. 1-31). London, Earthscan.

Slovic, P., Monahan, J. A., \& MacGregor, D. G. (2000). Violence Risk Assessment and Risk Communication: the Effects of Using Actual Cases, Providing Instructions, and Employing Probability vs. Frequency Formats. Law and Human Behavior, 24(3), 271-296. http://dx.doi.org/10.1023/A:1005595519944 
Swiss, Re. (2015). Natural catastrophes and man-made disasters in 2014: convective and winter storms generate most losses. Sigma n.2.

\section{Notes}

Note 1. The most common definition of "NatCat" is the one by EEA (2010) that includes:

- Flood: significant rise of water level in a stream, lake, reservoir or coastal region

- Storm: events caused by short-lived/small to meso scale atmospheric processes (strong winds usually in combination with heavy precipitation) in the spectrum from minutes to days

- $\quad$ Earthquake: shaking and displacement of ground due to seismic waves

Drought: extended period of time characterised by a deficiency in a region's water supply that is the result of constantly below average precipitation.

Note 2. Ex post government relief (provided after disaster) would reduce incentives to purchase insurance coverage. This is referred to as the "charity hazard", as defined by Browne and Hoyt (2000) and also Raschky, Weck-Hannemann (2007).

Note 3. One of the many examples is the excise taxes on petrol that date back to 1963 following the Vajont disaster.

Note 4. About this point: Slovic, Kunreuther and White (2000), Kunreuther et al., 2013.

Note 5. Risks that are uncorrelated are risks of which the incidence of loss is spread out, either in terms of time or in terms of the individuals suffering the loss. As long as the risks of the pool members are uncorrelated, that is statistically independent, the insurer can accumulate small premium from each insured and still have funds sufficient in any period to pay those losses that actually occur.

Note 6. For Italian case, see Monti (2002). In general, see Rea (1992). 